The importance of balance and postural control in the recovery of stroke patients

\author{
SILIȘTEANU Sînziana Călina ${ }^{1,2}$, ANTONESCU Elisabeta ${ }^{3,4}$, DUICĂ Lavinia ${ }^{3,5}$
}

Corresponding author: Elisabeta Antonescu, E-mail: elisabeta.antonescu@ulbsibiu.ro

1. Railway Hospital Iasi - Specialty Ambulatory of Suceava

2. "Stefan cel Mare" University of Suceava FEFS-DSDU

3. Lucian Blaga University of Sibiu, Faculty of Medicine, Sibiu, România

4. County Clinical Emergency Hospital, Sibiu, România

Abstract

5. Hospital of Psychiatry „Doctor Gheorghe Preda” Sibiu, România

Introduction.According to the criteria of WHO, stroke is a health condition that causes focal or global brain disorders (1), but without an apparent nonvascular cause. Stroke is considered the third leading cause of death in industrialized countries and accounts for $9 \%$ of all deaths, being considered one of the largest cases of disability in the world. Due to the medical, social and economic consequences that it causes, stroke is considered a public health issue. Purpose of research. The study starts from the idea that in the recovery of stroke patients it is important to have an individualized physiotherapy program adapted to the functional parts of each patient, having the role of improving the static and dynamic balance, of achieving postural control and finally functional independence. Material and method. The study included a number of 22 patients with sequelae stroke. They made physiotherapy, occupational therapy and occupational therapy sessions in the ambulatory, with the length of 1 hour, 3 times a week, in total 15 sessions. The evaluation of the patient was performed in the beginning of the treatment and at the end of it. Scales were used to assess mobility, static and dynamic balance, gait and functional independence. Results. The application of individualized treatment adapted to the functional body of each patient allowed a rapid recovery for the vast majority of the studied patients. The values obtained in the tests and evaluation scales are in accordance with the clinical evolution of the patients. Conclusions. The application of the treatment by kinetic therapy, work therapy and occupational therapy to the 22 patients, for a period of 3 weeks pointed out the reduction of pain, the improvement of movements, the recovery of transfers and gait, the postural improvement.

Key words: stroke, recovery, kinetic therapy, work therapy, occupational therapy,

\title{
Introduction
}

According to the criteria of WHO, stroke is a health condition that causes focal or global brain disorders (1), but without an apparent nonvascular cause. Some symptoms of the stroke can be similar to the symptoms of some tumours - gliomas ( motor, sensitive, cognitive dysfunctions ) (2) or with manifestations of the Alzheimer's disease (cognitive dysfunctions, the decrease in the functional independence, the decrease in the ability to carry out the daily activities) (3), health conditions that may be encountered in balance disorders. Countries with a low living standard are very often affected. Globally, stroke is the second leading cause of death in people over the age of 60 and the fifth leading cause of death in the 15-59 age group (4).

Stroke is considered the third leading cause of death in industrialized countries and accounts for $9 \%$ of all deaths, being considered one of the

largest cases of disability in the world. There are studies (3) that demonstrate the link between inflammation and a cerebral vascular event with an ischemic character such as stroke. Thus, the Creactive protein marker is correlated to the prognosis and severity of the disease, but it is also related to the degree of motor deficit quantified by the MRC scale (5). The number of patients diagnosed with stroke is increasing due to the aging of the population (4). Due to the medical, social and economic consequences that it causes, stroke is considered a public health issue (1).

In the US, but also globally, stroke is the leading cause of disability. Physiotherapy and occupational therapy that have a role in the motor recovery of limbs and gait are studied; however, the role of robotic therapy, stem cell therapy and repetitive transcranial magnetic stimulation is studied, too (6). 
In stroke, early recovery is very important for the social professional and family reintegration. In this context, the determination of the functional prognosis is useful to make the recovery plan (especially spontaneous) and the recovery of the deficit (1). It is known that some patients can recover completely in hours or days after a stroke, in comparison to other patients whose improvement is not obtained even after a long time. If the stroke patient was diagnosed prior to neurological suffering with a degenerative condition in the supporting joints, then the body's stability, posture and balance were affected, especially during the gait, which means that the recovery program will be individualized and focused on establishing the functionality (7).

A study (8) conducted in 2017 shows that the incidence of stroke is higher in men in comparison to women. Stroke is a heterogeneous health condition, but there is a mathematical probability that can be observed at the level of recovery $(9,10)$ which means that a mathematical regularity is taken into account. Thus, motor recovery is determined by the time parameter and is restricted in the first 3 months after stroke $(1,11,12)$. Significant improvements are found in the first weeks so that the recovery is uniform after $4-12$ weeks $(1,13)$.

After analyzing post-stroke recovery patterns, it was found that for the upper and lower limbs as well as for the trunk, the recovery pattern appears to be the same, leading to the idea that spontaneous motor recovery is determined by common underlying mechanisms. (1) The mechanisms underlying to spontaneous recovery, shown by the decrease in the primary motor deficits, are not known $(1,14)$. However, age is an independent element $(1,14,15,16)$ and the occurrence of stroke should not be linked to aging (16).

Studies $(1,12,17)$ show that there is a longitudinal regression mode for the recovery of the upper and lower limbs (especially in the first 10 weeks and $80 \%$ of the improvement is ensured), even the ability to walk $(12,17)$.

However, functional improvements depend on the development ability of certain adapted motor strategies. It is about learning to make up for lost motor functions and to substitute functions, a process that takes place more than 3 months after the stroke, during which the brain must adapt to the challenges of the environment.

It is known that stroke is associated to changes of the static balance (sitting position) and of the dynamic balance (orthostatism). In the lower limbs, the balance between the agonist / antagonist muscles is disturbed, whereas the modifications at the cortex level affect posture, balance and coordination (18).

The motor ability is very important and depends on 2 factors: restitution and substitution of function.

For a stroke patient, it is important to resume daily activities, walking skills, cognition and language.

The Basic Daily Activities (ADL) are consistent with the patients' clinical condition, the severity of the stroke $(19,20,21)$, the progress of motor activities in the first weeks $(1,22,23)$. Therefore, personal care recovers faster than dressing, walking, going up or down the stairs. As for the skills, it is important to actively control the radiocarpal joints, the extension of the toes, especially in the first 72 hours after a stroke (24, $25)$. The ability to walk is correlated to the motor defficit of the foot and the impossibility to move $(1,19,26,27,28)$. An important element for this purpose is the independent balance in the sitting and the force at the level of the hemiparetic leg. The improvement of the balance in orthostatism is the most important predicting factor to regain the independence of the walk. The independent walk correlates not only to the recovery of the motor function of the foot, but also to balance.

That is why the control of the balance is the most important prognosis factor in the recovery of the walk after stroke $(16,27,29,30,31,32,33)$.

In order to recover the static and dynamic balance and therefore of the gait, tests and scales can be applied: Trunk Control Test, PASS, Berg scale, "Up and go" tests and Tinetti. In order to detect the ability to achieve balance after stroke based on scales, $(1,34,35)$ it is necessary to evaluate the internal receptivity and the external adaptation reaction $(1,36)$. Very important is the external reaction by which the orthostatic balance is actually associated to modifications in the hip performance. $(37,8,39)$ The motor recovery of the lower limb is not always associated to the functional recovery of the gait (1).

The internal response is limited because it cannot be quantified clinically and it does not provide data 
related to the worsening or improvement of the patient's condition (35).

The recovery of stroke patients is complex and involves the re-education of primary deficiencies, the promotion of adapted motor strategies in order to obtain compensation of a function, the recovery of basic daily activities (ADL) .

Scales for mobility, static and dynamic balance can be used to assess the postural control.

\section{Purpose of research}

The study starts from the idea that in the recovery of stroke patients it is important to have an individualized physiotherapy program adapted to the functional parts of each patient, having the role of improving the static and dynamic balance, of achieving postural control and finally functional independence.

\section{Material and method}

The study included a number of 22 patients (40.91\% women and $59.09 \%$ men) with sequelae stroke. They made physiotherapy, occupational therapy and occupational therapy sessions in the ambulatory, with the length of 1 hour, 3 times a week, in total 15 sessions. Kinetic therapy included passive and active exercises (in bed and at the edge of the bed), balance exercises, transfers (in orthostatism) and gait training. The evaluation of the patient was performed in the beginning of the treatment and at the end of it. Scales were used to assess mobility, static and dynamic balance, gait and functional independence.

The criteria for inclusion in the study were: age 40-70, patients with clinical and imaging diagnosis of stroke, with hemiparesis, without comorbidities in decompensated stages, patients who agreed to participate in the study.

The exclusion criteria were: age $<40$ and $>70$, patients with neurological and mental disorders, cognitive and speech disorders, patients with associated musculoskeletal disorders, associated heart and respiratory disorders and patients who did not agree to participate.

The study was conducted according to the rules of ethics and deontology in force.

In this context the following were applied: VAS scale for pain assessment, BERG scale for balance, movement skills scale for mobility assessment, PASS scale, Up and Go test and Tinetti for balance, postural control, gait.
The postural assessment scale for stroke patients (PASS) allows the assessment of sitting balance and orthostatism (40). It includes 12 items and evaluates the performances during the period of keeping / changing the lying position, sitting and orthostatism.

The first part evaluates the possibility of keeping the posture through 5 items rated $0-3$, whereas the second part evaluates the ability to change the posture from lying to sitting, then sittingorthostatism, with a score between 0-3. The maximum score is 36 , which is useful to assess functional independence $(1,41)$ PASS is a functional balance test used especially in stroke patients with marked balance deficit. It is especially useful in the beginning of the poststroke recovery period (1).

Another possibility to assess the ability of the stroke patient to achieve static and dynamic balance is the Berg scale with 14 items and a maximum score of 56 points. It is considered a reference (1) in the assessment of balance in stroke patients and is considered a valid, reliable and sensitive test for stroke patients $(1,37,41,42,43)$. Thus, for balance, the Berg scale quantifies 14 actions with values from 0 to 4 .

For mobility, the scale of movement skills is used and follows 10 actions quantified between $0-2$. For the static, dynamic and walking balance, the Up and Go test and Tinetti test can be used.

Virtually all these functional tests follow balance, postural control and transfers.

The studied patients were observed in terms of behavior, cognition and motor function. It was found that patients spend $35 \%$ of the day in bed, out of which $28 \%$ resting and only $10 \%$ were involved in activities that could improve mobility and prevent complications.

During the treatment, the contact with the physiotherapist represented $4.16 \%$ and only 5 days / week. At weekends, even if they repeated the physical therapy program at home, it was not the intensity with which they worked in the physical therapy room and were supervised.

The objectives of the recovery program were: pain reduction, re-education of the grip, increased muscle strength, the re-education of balance and postural control, re-education of gait, stability, training to resume daily activities and an increase in the quality of life. 
Following the data collection, it is found that out of the 22 patients in the study group, a number of 13 $(59.09 \%)$ were men and 9 (40.91\%) women.

Table no. 1 Distribution of patients by age groups

\begin{tabular}{|c|c|c|c|c|}
\hline gender/years & $40-50$ years & $51-60$ years & $61-70$ years & total \\
\hline male & 1 & 7 & 5 & 14 \\
\hline female & 3 & 3 & 3 & 9 \\
\hline total & 4 & 10 & 8 & 22 \\
\hline
\end{tabular}

It was found that there were 4 patients $(18.19 \%)$ in the age group of $40-50,10$ patients $(45.45 \%)$ in the age group of 51-60 and 8 patients $(36.36 \%)$ in the age group of 61-70..

Distribution of patients by age groups and gender

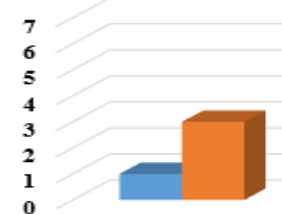

$40-50$ years

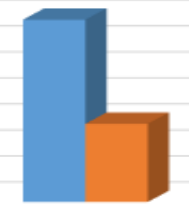

51-60 years

male memale

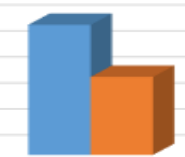

61-70 years
Graph no. 1 Distribution of patients by age groups and gender

\section{Statistical analysis}

The data obtained in the evaluation were processed in Microsoft Excel files and the median, standard deviation were used, and the t-student test was applied to compare the results and confirm the hypothesis. The results are considered statistical significant for $\mathrm{p}<0.05$.

\section{Results}

In the study group, the pain was evaluated with the help of the VAS scale and it was found at the time of $\mathrm{T} 2$ of the assessment a reduction of the pain phenomenon by $41.67 \%$, as shown in the table.

Table no. 2. Evolution of pain using the VAS scale

\begin{tabular}{|c|c|c|}
\hline median & T1 & T2 \\
\hline VAS & $6 \pm 0.51$ & $3.5 \pm 0.59$ \\
\hline
\end{tabular}

By applying the BERG scale, it was found that the execution of the movements improved by $22.82 \%$ at the time of $\mathrm{T} 2$ of the evaluation.

The Tinetti test shows an improvement in some components of gait by $22.82 \%$ at the time of $\mathrm{T} 2$ of the evaluation, which explains the increase in the possibility of movement in patients to gain functional independence.

The Up and Go test also showed an increase of $53.85 \%$ at time $\mathrm{T} 2$ compared to time $\mathrm{T} 1$, which shows the adaptation of patients to the new functional status and better performance of transfers and gait. As for the maintenance and change of patients' posture at different times, static and dynamic, there is an improvement of $40.74 \%$ at the postural assessment scale (PASS) at the final evaluation moment. The results can be found in Table 3 and in Graph 3.

Table no. 3. Evolution of the values of the scales for balance

\begin{tabular}{|c|c|c|c|c|c|c|c|c|}
\hline SCALE & Ipand $G$ & & BERG & & INETTI & & PASS & \\
\hline Statistical/moment & Il & I2 & Il & I2 & Il & I2 & Il & I2 \\
\hline median/std der & 6.5. 51.1 & $10 \pm 1,13$ & $35,5 \pm 3,52$ & $46 \pm 3,32$ & $7 \pm 0.73$ & $11 \pm 0.81$ & $16 \pm 2.35$ & $27 \pm 3.36$ \\
\hline
\end{tabular}

\section{Evolution of balance scales}

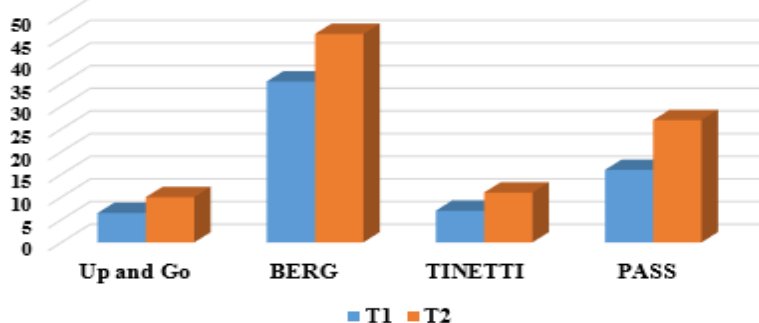

Graph. no. 2 Evolution of the values of the scales for balance

The evolution of the 22 patients on the Up and Go scale is shown in Graph no. 5.

There is an improvement in transfers, in the vast majority of patients, with statistically significant results, but there have also been cases of patients $5,7,11,15,20$ in which the evolution is longer in terms of recovery.

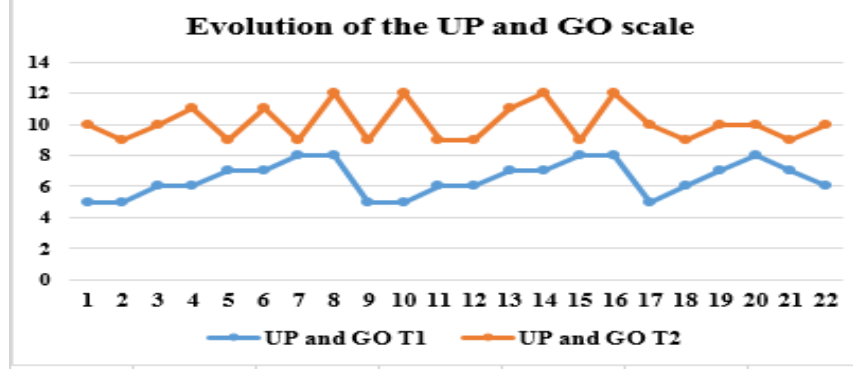

Graph no. 3. Evolution of patients in the Up and Go test

At the BERG scale, the improvement of the movement is statistically significant in all patients.

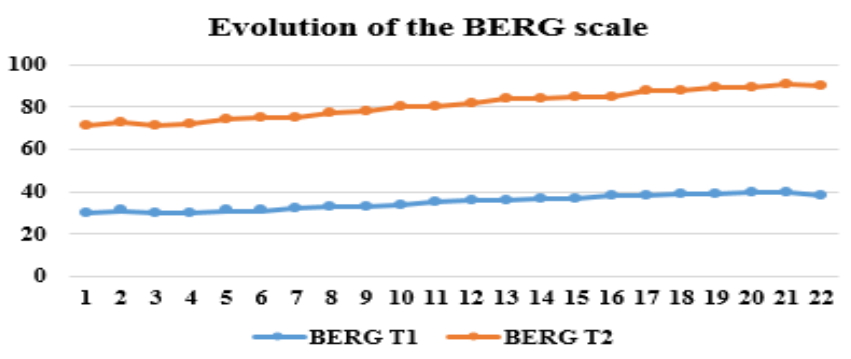

Graph no. 4. The evolution of the patients' mobility through the Berg scale 
The improvement of the gait, found by the Tinetti scale, is statistically significant in patients, less in patients $7,8,11,20$.

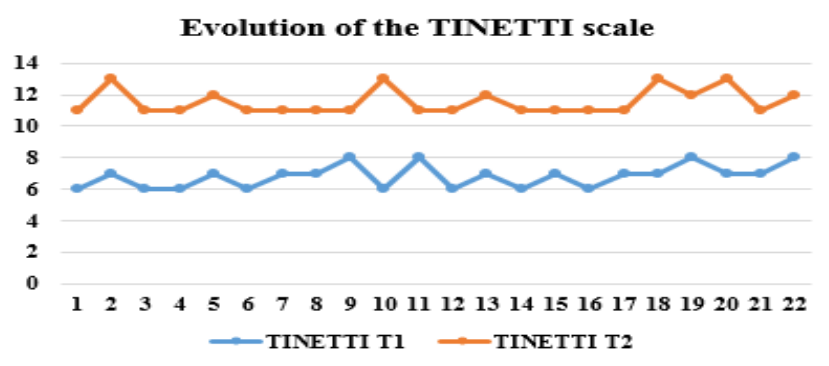

Graph no. 5. The evolution of the patients' gait by using the Tinetti scale

The postural evolution by the PASS scale, recorded statistically significant results in the study patients, except for patients 7, 9, 15, 20.

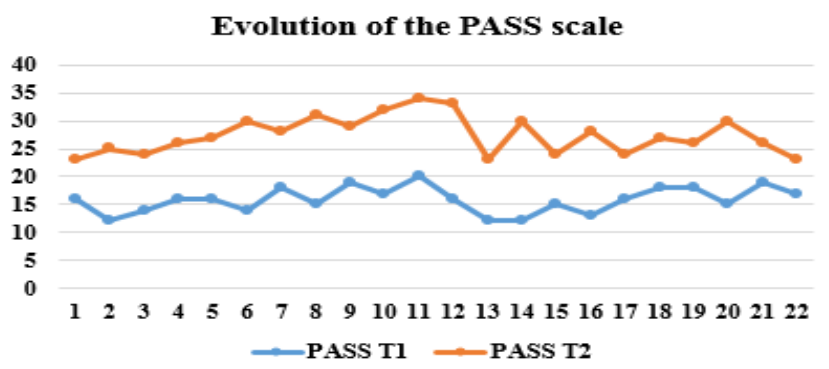

Graph no. 6. Postural evaluation of the patients by the PASS scale

\section{Discussions}

At the scales applied in this study, the results obtained are statistically significant, as shown by the results of the applied t-student test where the values are $<0.05$.

Table no. 4. The values of the t-student test

\begin{tabular}{|c|c|c|c|c|}
\hline SCALE & Up and Go & BERG & TINETTI & PASS \\
\hline test t-student & 0.0276 & 0.0118 & 0.0271 & 0.0388 \\
\hline
\end{tabular}

Also for pain, assessed using the VAS scale, the results are statistically significant, the value of $p$ being $<0.05$, namely $\mathrm{p}=0.0392$.

The application of individualized treatment adapted to the functional body of each patient allowed a rapid recovery for the vast majority of the studied patients, with small exceptions in patients $5,7,8,9,11,15,20$. They were found to be slow in recovery either on mobility, posture or gait. In such a context, these patients will need a readjustment of the recovery program to the clinical-functional body of each patient, and on the other hand their awareness that the recovery program has results after working in the physiotherapy room but also at home.
The values obtained in the tests and evaluation scales are in accordance with the clinical evolution of the patients.

\section{Conclusions}

The application of the treatment by kinetic therapy, work therapy and occupational therapy to the 22 patients, for a period of 3 weeks (a 1-hour session 3 times a week) pointed out the following:

-the reduction of pain in all patients, with statistically significant results

-the improvement of movements in all patients, the results being statistically significant

-the improvement of gait in the studied patients, with statistically significant results, but with a slowdown in recovery in 4 patients

-the recovery of transfers and gait in the studied patients, with statistically significant results, but also with a slower recovery in a number of 5 patients

- the postural improvement in 19 of the 22 patients, with statistically significant results .

After taking into account the obtained results, it is necessary to re-evaluate the patients who presented delayed evolution and to readjust the recovery program to their clinical-functional status.

The degenerative health conditions, the cardiac ones, the hip fracture, may severely

influence the prognosis of the stroke and the patient 's quality of life.

All patients need a careful assessment of their functional, motor, sensory, cognitive abilities in order to choose recovery strategies. Thus, some patients will have a recovery program based on reducing primary deficits, whereas another group will have a recovery program with a functional purpose, based on the compensation of a function.

Furthermore, it is necessary for the patients' families to become more involved in their recovery program, positively influencing social, family and professional reintegration.

Declaration of conflict of interests: The authors declare no conflict of interests and no sponsorship. All authors have read and approved this publication and had equal scientific contribution in publishing this material.

Informed consent: An informed consent was obtained from the patients included in this study. 


\section{Reference}

1. Stam HJ, Buyruk HM, Melvin JL, Stucki G, Burggraaf IB. Recuperarea medicala de faza acuta. Ed. Universitara „Carol Davila" Bucuresti, 2012, ISBN:978-973-708-879-6

2. Grosu F, Ungureanu A, Bianchi E, Moscu B, Coldea L, Stupariu AL, Pirici I, Roman-Filip C. Multifocal and multicentric low-grade oligoastrocytoma in a young patient. Rom $\mathrm{J}$ Morphol Embryol 2017, 58(1):207-210

3. Birlutiu V, Stef L, Cernusca Mitariu SI, Roman Filip C, Duica L, et al. The Biochemical Biomarkers Determination in Alzheimer

Dementia.Rev.Chim.(Bucharest).2018;69(11)

4. Feigin VL, Lawes CM, Bennett DA, BarkerCollo SL, Parag V. Worldwide stroke incidence and early case fatality reported in 56 population-based studies: a systematic review. Lancet Neurol. 2009 Apr;8 (4):355-69

5. Totan M, Antonescu E, Catana MG, Cernusca Mitariu MM, Duica L., Roman Filip C, et al. C-Reactive Protein-A Predictable Biomarker in Ischemic Stroke. Rev.Chim. (Bucharest).2019; 70(6)

6. Langhorne P, Bernhardt J, Kwakkel G. Stroke rehabilitation, The Lancet, Volume 377, Issue 9778, 14-20 May 2011, Pages 1693-1702 .

7. Danelciuc FT, Silisteanu SC, Danail S. The increase of the life quality for patients who had a cerebrovascular accident by using the MBT physiotherapy device. Balneo Research Journal;2017. 8 (1), 40-45

8. Thrift AG, Thayabaranathan T, Howard G, Howard VJ, Rothwell PM, et al. Global stroke statistics. International Journal of Stroke, January 1, 2017, Volume: 12 issue: 1, page(s): 13-32.

9. Kwakkel G, Kollen B, Lindeman E. Understanding the pattern of functional recovery after stroke:facts and theories.Restor Neurol Neurosci.2004 A: 22(3-5):281-99

10. Koyama T, Matsumoto K, Okuno T, Domen KA. New method for predicting functional recovery of stroke patients with hemiplegia:logarithmic modelling. Clin Rehabil. 2005 Oct:19(7):779-89

11. Dobkin BH. Rehabilitation and functional neuroimaging dose-response trajectories for clinical trials. Neurorehabil NEURAL Repair. 2005A Dec:19(4):276-82

12. Kwakkel G, Kollen B. Twisk J. Impact of time on improvement of outcome after stroke. Stroke. 2006 A Sep:37(9):2348-53

13. Kwakkel G. Impact of intensity of practice after stroke:issues for consideration. Disabil Rehabil. 2006 B Jul 15-30: 28 (13-14):820-30

14. Dobkin BH. Confounders in rehabilitation trials of task-oriented training: Lessons of designs of EXCITE and SCILT multicenter trials. Neurorehabil Neural Repair. 2007;21:313

15. Kwakkel G. Impact of intensity of practice after stroke:issues for consideration. Disabil Rehabil. 2006 B Jul 15-30: 28 (13-14):820-30

16. Bagg S, Pombo AP, Hopman W. Effect of age on functional outcomes after stroke rehabilitation. Stroke. 2002 Jan:33(1):179-85

17. Kollen B, van de Port I, Lindeman E, Twisk J, Kwakkel G. Predicting improvement in gait after stroke: a longitudinal prospective study. Stroke. 2005 Dec:36(12):2676-80

18. Danelciuc FT, Danail S, Silisteanu SC. A trial regarding the baropodometric indexes for patients who had a cerebrovascular accident. Balneo Research Journal;2017. 8 (3), 129-135

19. Meijer R, van Limbeek J, Peusens G, Rulkens M, Dankor K, Vermeulen M, et al. The stroke Unit Discharge Guideline, a prognostic framework for the discharge outcome from the hospital stroke unit. A prospectice cohort study. Clin Rehabil.2005 Oct;19(7):770-8

20. Kwakkel G, Veerbeek JM, Harmeling-van der Wel BC, van Wegen E, Kollen BJ. Early Prediction of functional Outcome after Stroke (EPOS) Investigators. Diagnstic accuracy of the Barthel Index for measuring activities of daily living outcome after ischemic hemispheric stroke:does early poststroke timing of assessmnent matter? Stroke.2011 Feb:42(2):342-6

21. Kwakkel G, van Peppen R, Wagenaar RC, Wood Dauphinee $\mathrm{S}$, et al. Effects of augmented exercise therapy time after stroke: ameta-analysis. Stroke.2004 B Nov; 35(11):2529-39.

22. Verheyden G, Nieuwboer A, Wit LD, Thijs V, Dobbellaere J, et al. Time cours or trunk,arm leg and functional recovery after ischemic 
stroke. Neurorehabil Neural Repair.2008 MarApr;22(2):173-9

23. Formisano R, Pantano P, Buzzi MG, Vinicola V, Penta F, Barbanti P, Lenzi GL. Late motor recovery is influenced by muscle tone changes after stroke. Arch Phys Med Rehabil.2005 Feb;86 (2):308-11

24. Smania N, Paolucci S, Tinazzi M, Borghero A, Manganotti P, Fiaschi A, Moretto G. Active Finger Extension. Stroke 2007: 38:1088-1090

25. Fritz SL, Light KE, Patterson TS, Behrman AL, Davis SB. Acive finger extension predicts outcomes after constraint-induced movement therapy for individuals with hemiparesis after stroke. Stroke .2005 Jun;36 (6):1172-7

26. Wandel A, Jørgensen HS, Nakayama H, Raaschou HO, Olsen TS. Prediction of walking function in stroke patients with initial lower extremity paralysis:the Copenhagen Stroke Study. Arch Phys Med Rehabil.2000 Jun;81(6):736-8

27. Veerbeek JM, Van Wegen EE, Harmeling-Van der Wel BC, Kwakkel G. EPOS investigators. Is accurate prediction of gait in nonambulatory stroke patients possible within 72 hours post stroke: The EPOS study.Neuroreahabil Neural Repair.2011 Mar Apr;25(3):268-74

28. Kollen B, Kwakkel G, Lindeman E. Time dependency of walking classification in stroke. Phys Ther. 2006 B May;86(5):618-25

29. de Haartt M, Geurts AC, Dault MC, Nienhuis B, Duysens J. Restoration of weight-shifting capacity in patients with postacute stroke: a rehabilitation cohort study. Arch Phys Med Rehabil.2005 Apr;86(4):755-62

30. de Haart M, Geurts AC, Huidekoper SC, Fasotti L, van Limbeek J. Recovery of standing balance in postacute stroke patiens: arehabilitation cohort study. Arch Phys Med Rehabil.2004 Jun;85(6):886-95

31. Geurts AC, de Haart M, van Nes IJ, Duysens J. A review of standing balance recovery from stroke. Gait posture.2005 Nov;22(3):267-81

32. van de Port IG, Kwakkel G, Schepers VP, Lindeman E. Predicing mobility outcome one year after stroke: a prospective cohort study.J Rehabil Med.2006 Jul;38(4):218-23

33. Buurke JH, Nene AV, Kwakkel G, ErrenWolters V, Ijzerman MJ, Hermens HJ. Recovery of gait after stroke"what change?
Neurorehabil Neural Repair.2008 NovDec;22(6):676-83

34. Portney L, Watkins M. Foundations of Clinical Research: Applications to Practice. 3rd ed Norwalk, CT: Appleton \& Lange; 2007.

35. de Yébenes Prous MJ, Rodríguez Salvanés F, Carmona Ortells L. Responsiveness of outcome measures [in Spanish]. Reumatol Clin. 2008;4:240-247.

36. Terwee CB, Dekker FW, Wiersinga WM, et al. On assessing responsiveness of healthrelated quality of life instruments: guidelines for instrument evaluation. Qual Life Res. 2003;12:349-362.

37. Blum L, Korner-Bitensky N. Usefulness of the Berg Balance Scale in stroke rehabilitation: a systematic review. Phys Ther. 2008;88:559566.

38. Godi M, Franchignoni F, Caligari M, et al. Comparison of reliability, validity, and responsiveness of the Mini-BESTest and Berg Balance Scale in patients with balance disorders. Phys Ther. 2013;93:158-167.

39. King LA, Priest KC, Salarian A, et al. Comparing the Mini-BESTest with the Berg Balance Scale to evaluate balance disorders in Parkinson's disease. Parkinsons Dis. 2012;2012:375419.

40. Pendlebury ST, Cuthbertson FC, Welch SJ, Mehta Z, Rothwell PM. Underestimation of cognitive impairment by Mini-Mental State Examination versus the Montreal Cognitive Assessments in patients with transient ischemic attack and stroke: a population-based study. Stroke.2010Jun;41 (6):1290-30.

41. Mao HF, Hsueh IP, Tang PF, Sheu CF. Hsieh C.L.,Analysis and comparison of the psychometric properties of three balance measures for stroke patients. Stroke. 2002; 33:1022-7

42. Au-Yeung SS, Ng JT, Lo SK. Does balance or motor impairment of limbs discriminate the ambulatory status of stroke survivors? Am J Phys Med Rehabil. 2003;82:279-283.

Stevenson TJ. Detecting change in patients with stroke using the Berg Balance Scale. Aust J Physiother. 2001;47:29-38. 